\title{
A TURBULENT BUSINESS ENVIRONMENT AS A CRITERIA OF OPTIMAL STRATEGY TO ENTER INTERNATIONAL MARKETS
}

\author{
Ludmila Bahmane ${ }^{1}$
}

\begin{abstract}
This work provides an analysis of marketing solutions and developments algorithm for Latvian enterprises entering into foreign markets based on an example of 185 studies made under the supervision of the author. The proposed algorithm is a part of the pedagogical activities in higher education institution of Latvia (RISEBA) over the last 10 years and it suggests the training of new marketing solutions development techniques in conditions of the turbulent business environment. The application of the proposed algorithm assumes the use of modern marketing technologies, including matrix methods, cluster, and screening analysis. The algorithm proposed is being analyzed on the example of Latvian enterprises. This work describes the use of the author's proposed matrix of "consumer's demand for creativity (novelty)," that is relevant in the development of creative marketing management solutions of such business spheres, where the novelty of products (services) is an important competitive advantage. The high versatility, simplicity and availability is proven for mastering and using the proposed algorithm.
\end{abstract}

JEL Classification Numbers: A29, D47, M31; DOI: http://dx.doi.org/10.12955/cbup.v5.893

UDC Classification: 339.5

Keywords: marketing management, turbulent business environment, "consumer's demand for creativity" matrix, cluster, matrix, screening analysis.

\section{Introduction}

Marketing management - for over 100 years, management has been forming the science of organization management, including business structures. Up to the middle of the fifties in the 20th century, marketing was considered to perform almost the same functions as sales. The sixties and the beginning of the seventies have become a golden era due to the new concept of marketing, which has become a basic philosophy of business at the time. Let's try to focus on a few aspects of organization marketing factors (Kotler \& Keller, 2012) that specify an external business environment. The external business environment can't be constant, it is changing. As of such, it is possible to distinguish between the environment with slow changing parameters and the environment with fast and unpredictable changes. When some time has passed from that day, such an environment can be defined as the "calm" environment. Managers at that time were to organize their enterprises in such a way, that all opportunities of such an environment have been utilized completely. The situation of business structures becomes more complicated due to new conditions. With each year company management must consider not only increasing the number of environmental factors influencing the organization, but their global nature as well. Due to globalization with the increased number of management factors and their new features, there has been a new realization that management situations become unpredictable. There has been a new recognition of marketing managements in conditions of unpredictable, rapidly changing, and turbulent environments. New conditions require an understanding of an entirely new field of jurisprudence, marketing, and recognition of new cultural values. For the small and medium business of small states, such management requirements are especially difficult to realize. To achieve success, companies must compete in foreign markets and withstand competition with foreign companies at home as well. For Latvian entrepreneurs, an important and objective factor is the size and development level of the national market. Per the latest data, there are at most 1.97 million inhabitants in Latvia (2016).

\section{Turbulent business environment as a new factor of marketing management}

In modern marketing, several authors have been researching the factor of environmental changes as specific organization factor. Thus, Charles F. Sabel and Jane E. Prokop (1997) have stated in their work "Stabilization through reorganization" (Sabel \& Prokop, 1997) and Michael Hammer and James Champy in their book "Reorganization of corporation" (2009), that up to about 1975, the environments of organizations have been stable with uncommon global cataclysms and the changes in such environments were insignificant. Rapidly changing environments can be characterized by increased instability, unpredictability, and the behavior of managers has become greatly complicated

\footnotetext{
${ }^{1}$ RISEBA University, Riga, Latvia, ludmila.bahmane@inbox.lv
} 
when compared to the behavior in conditions of the "calm" environment. In time, the quantity changes into a new quality, i.e. global changes arise, which lead themselves to the new concept of "global environment" (Lambin, 1994; Porter, 2008). Because of environments transitioning from "calm" state to rapidly changing, global changes of main economic environmental indicators have occurred.

As a consequence, the following characteristics may be noted: the rapid shortening of product's life cycle; decreased products development time; maintaining warehouses becomes unprofitable; changes in requirements of technical subsystem of organization; increased complexity of products; changes in relationships between customers and manufacturers (confidence in competence); impracticality of maintaining own expert science intensive services; consumer dictates suppliers; increased toughness of competition; and pricing is not the most important factor in cooperation. As a result, the management attempts to find new methods and ways to manage businesses.

So, marketing management shows up. This means, that alongside to P. Kotler, new gurus of marketing appear such as Lambin J. J. (Lambin, 1994), and for instance, Sweden marketing school (Best, 2014). However, not always new management opportunities could reach small and medium business before old market economy problems are transformed. The crisis has become global. The fragmentation of markets continues to grow; the bounds of traditional markets become blurred due to substitutes and new technologies. Purely national markets transform into global and crisis management appears (Kotler \& Keller, 2012). Specialists begin to mention that during the last 10 years, the business environment has changed entirely (Porter, 2008; Best, 2005). The concept of turbulence came from physics, which soon enough has been transformed into the concept of "turbulent business environment" (Lambin, 1994; Bahmane, 2010). There are not only forecasted changes of environmental factors, but the rules themselves alter as well, which describe how organizations should operate. And these rules change rapidly and unpredictably. The latest example of such changes are: withdrawal of Great Britain from the EU, new American policies of Trump, political factors (sanctions and counter-sanctions of the Russian Federation), which require to dismiss or to reprofile entire fields of the food industry of Latvia completely. What will happen to Latvian companies? Nobody knows that. How should management of these organizations operate for small and medium business?

It is considered, that in such turbulent environments the most important thing is the increased ability of organizations to adapt and survive (Hammer \& Champy, 2009). A turbulent environment dictates specific requirements, which should be obeyed by enterprises. The conditions may be confused with requirements, because managers of a new company, irrelevant of its strong position, must "catch up" onto changes of the environment and make changes to their company in due time, otherwise, after some rather short time it will be too late to take such actions and former positions will be lost to more modern competitors. In short, these requirements are as follows: decreased the size of the organization; reorganization (reengineering); constant monitoring of the environmental situation; the immediate response to changes of the environment; the launch of "in time" production systems. In conditions of turbulent business environments, the enterprises must have clearly recognizable advantages, which should be developed for the organization to operate in advance by using a proactive marketing strategy instead of a reactive one. Such competitive advantages can be estimated by using a "Demand for novelty" matrix (Bahmane, 2005).

The ability to see new opportunities in the big global market becomes the most important conditions of survival for small and medium business, especially in small countries. The analysis in strategical marketing decision making and generation allows the author to state that: by using known (but little used) technologies to generate marketing solutions, it is possible to find an adequate solution for turbulent environments, including a strategical one (Bahmane, 2010).

\section{Algorithm of marketing decision making in a turbulent business environment}

For the criteria of optimality for marketing decisions generation in conditions of a turbulent environment, the following factors are considered:

1. decreasing risks;

2. direct search of maximum possible number of solution variants;

3. reliance upon developing competences. 
It is important to formulate an algorithm as a sequence of logical activities to solve specific tasks and to teach modern analytical methods that provide a fast and direct search of possible marketing solutions, the choice of the effective one, and if there is none, to develop and offer one's own solutions without fear. To achieve this, the manager should be able to consciously make:

- Decisions of the 1-st type - environment is developing predictably, thus solutions have a predetermined algorithm already known to manager.

- Decisions of the 2-nd type - from a set of multiple possible solutions, the manager must choose the most appropriate one. It is necessary to know the existing criteria to choose effective solutions.

- Decisions of the 3-rd type - solving untypical tasks. Manager can analyze unfamiliar situations and information, and generate new information.

- Decisions of the 4-th type - the ability to see new connections and opportunities, as well as the ability to generate completely new information based on this information in conditions of a turbulent business environment. For problems of this type the elements of creativity become absolutely required.

It is important, that in addition to these widely used and well-known matrices (Porter, Ansoff, Boston, McKinsey, SWOT) (Ansoff, 2007), the possibilities of the author's matrix, "solutions novelty demand for novelty by consumers", application are investigated (Bahmane, 2005) (see. Figure 1).

\begin{tabular}{|c|c|c|c|}
\hline \multicolumn{4}{|c|}{ Figure 1: Matrix of "Solutions novelty - demand for novelty by consumers" } \\
\hline $\begin{array}{l}\text { Level of management } \\
\text { solutions novelty }\end{array}$ & & & \\
\hline Maximum & $\begin{array}{l}2 \\
\text { Strategy of quality } \\
\text { increase (company image } \\
\text { strategy, strategy of } \\
\text { leadership in the field) }\end{array}$ & $\begin{array}{l}4 \\
\text { Benchmarking strategy } \\
\text { (strategy of new products } \\
\text { superquality, strategy of } \\
\text { world leadership) }\end{array}$ & \multirow[b]{3}{*}{$\begin{array}{l}\text { Demand for novelty } \\
\text { by consumers }\end{array}$} \\
\hline Minimum & $\begin{array}{l}1 \\
\text { Strategy of proven quality } \\
\text { (product brand strategy) }\end{array}$ & $\begin{array}{l}3 \\
\text { Strategy of new products } \\
\text { (strategy of innovator } \\
\text { image, strategy of niche } \\
\text { leader) }\end{array}$ & \\
\hline & Minimum & Maximum & \\
\hline
\end{tabular}

\section{Algorithm of securing strong position in foreign market}

The survival of small and medium businesses in the turbulent and rapidly changing conditions of the Latvian market depends entirely on the targeted search for new exporting opportunities by enterprises themselves. An example of a small Latvian company SIA ProBaltic has shown, that in conditions of market internationalization, the use of previously built databases, as well the application of screening analysis and matrix methods, allows finding and choosing the optimal marketing strategy to secure a niche in international markets by method of cabinet studies (Bahmane, 2010). The method of screening analysis, that has been mastered by example of studying 185 Latvian enterprises, indicates that there exists a specific searching algorithm to find the optimal solution with the choice of specific countries and markets, where products (or services) of a company will be able to secure a competitive niche. The main purpose of the company is to secure strong positions in foreign markets, by using the fastest direct search of possible marketing solutions.

Algorithm implementation stages.

1. Screening-analysis method (Cherenkov, 2006) allows for the solving of practically almost unsolvable task: to analyze market opportunities in the most comprehensive way with limited possibilities of the company (staff, time, resources). This can be used to define a list of high priority countries for further analysis. 
2. If the environment is turbulent or rapidly changing, the screening analysis allows change of search criteria and to define multiple lists of high priority countries, which enable additional corrections to the international marketing strategy. So, when choosing some specific criteria and adapting them to specific conditions, the strategies of segmentation and positioning can be developed.

3. The environmental scanning method (Cherenkov, 2006) allows to separate specifics of the macro-environment and micro-environment, which can be used to determine a niche in potentially attractive countries, where the specific company can be competitive.

4. The Marketing-mix model use -7P(9P), which allows the company to ensure a full match in the needs of the target consumers in each of the chosen countries with the marketing capabilities of the company.

Screening analysis allows creating a list of high priority exporting countries by using a direct search among the 236 countries in the world in MS Excel software with conditional formatting tools. This method has been successfully used in RISEBA for 5 years in home tests of International marketing by students of the $3^{\text {rd }}$ year for a wide variety of business structures - from small gambling business to banking. More difficult variants, which include the search for optimal selection criteria, comparative analysis of selected countries, and in-depth research of competitive niches, become bachelor's or master's degree thesis works.

The realization stages of optimal niche searching algorithm for a specific company in market globalization conditions can be summarized as follows below:

1. The object of the research is determined - a real company operating on the Latvian (European) market. The situation of the company is analyzed in conditions of the Latvian (or other national) market. The symptoms of problems, the base problem, and its research design are determined. A graph of the problem and solutions is designed.

2. The influence of micro-environmental factors on the operation of the company is determined with the PEST methods. The business environment type is determined: Stable? Changing? Turbulent? What is the company's vision in these conditions?

3. The base market is conceptualized. The macro segmentation of the market is performed by using one of the well-known methods (Abel's method, "fish," "net," 3D matrix).

4. Based on the matrix of "solutions novelty - demand for novelty by consumers" (Bahmane, 2005) an active marketing development strategy can be defined for the analyzed company based on the company's competence and specific business development trends.

5. The base for further analysis is determined: the features of the company's activities that make products (services) unique and competitive.

6. Based on the matrix of "local-global forces" the trends of advancement in international markets can be determined. The condition for search of new markets is defined - the strategy of the company is formed - standardization or adaptation, and the target of further research is determined: finding new markets, which are ready to accept the products of the company or finding the products, which are in high demand in markets known to the company. This decision is determined by the competitive (unique) features of the company's products (services).

7. The screening analysis is performed to determine a list of high priority countries for further analysis. The screening analysis makes use of 4 filters which remove from a set of all countries those not matching the specific criteria.

- 1 -st filter. Potential is evaluated - macro-environment.

- Review: socially-cultural norms, politically-legal norms, the economical state of countries, the geographical location.

- Supposed selection criteria: customs tax, average income level per capita, the distance between exporting and importing countries, the population size of importing country, political disagreements between states (economic sanctions, embargoes).

- 2-nd filter. Particularities of accepting specific products at the given location

- Selection criteria evaluated: religious factors, informational provisions, historical premises, ethnical norms and traditions, market development stages. 
- 3-rd filter. Specific factors influencing export.

- Selection criteria evaluated: competition at the local market, similar substitutes of specific product, forecasts and real data on similar product sales at the market, acceptance rate by consumers, market entering expenses.

- 4-th filter. Target markets. Thus, a list of high priority countries is created for the search of a specific niche. From 236 available countries, only few are considered further, which is much easier.

8. Based on a list of selected countries (one, two and three) the environmental scanning analysis is performed by sections: economical, politically-legal, socially-cultural, technological.

9. Based on the McKinsey matrix (Kotler \& Keller, 2012), the exporting strategy to the specific list countries is determined (from export to investments).

10. Competition analysis (per Porter) allows defining the most dangerous factors and risks for a company in conditions of the unstable environment. SWOT is constructed (TOWS).

11. Micro segmentation of the market is performed; the most attractive segment of the market is determined. VALS2, GLOBAL SKAN, (Kotler \& Keller, 2012). By using a correlation or cluster analysis, the variants of product positioning are proposed in general and for the selected segment.

12. The distribution channels of the product are determined - how they match requirements of the target market segment in the selected country.

13. The price policy is determined and company tactics with an orientation to the selected market segment by maximally using a "price-quality matrix," common competition matrix (Porter, 2008).

14. Communications strategy is developed considering specifics of the target consumer segment in the selected country.

Let us study one of the examples of the screening analysis application for exporting Latvian bakery "Lāči" products to potential (it is limited liability company founded in 1993) markets. The main activities: baking high quality bread per old-time Latvian traditions and making original confectionery. From a small bakery, "Lāči" has grown into a modern and stable enterprise with 200 employed persons and makes about 5 tons of bread daily. Net turnover is over 7.5 million EUR. Bakery "Lāči" creates and improves new products which are in high value not only in Latvia, but also abroad. The list of partnering countries of "Lāči" is: Russia, Ukraine, Estonia, Great Britain, Australia, Japan, the United States of America. The main market of "Lāči" products is ethnical. The niche for ethnical trading is open in markets when demand for exotic products from native populations allows immigrants to convert their contents and symbols of their ethnicity into products for profit. Selling exotic products and services is a rather profitable direction of business development, since immigrants offer products not readily available to get or be presented from anyone else. This is the advantage of "Lāči" products (especially of rye bread), which in the US and Great Britain markets is of high demand among immigrants from post-soviet states.

The product is standard for Latvia however, for exporting purposes a partial adaptation can be made; for example, the sugar amount in the product can be altered, depending on the customers' preferences. The trademark is not about to be changed however, sometimes the products are sold under private trademarks of partners, which can be more recognizable by local customers. The package of products can be altered as well. The price is determined by considering expenses, logistics, and risks in Europe, while for non-European countries additionally customs taxes are included, and when necessary corrections by the market are made. Air transportation is used for making deliveries to far countries: Japan, USA and Australia. The bread is frozen; other products can have a storage life of up to one year. Delivery of products to the USA takes from one month to 6 weeks, and to Australia - about 2 months. Based on the matrix of "Local-global forces," the company plans to work with standard Latvian products and adapt them only for the end consumers, instead of the target markets. In other words, it is more logical for the company to enter the transnational environment.

Based on the matrix of "Market attractiveness - development costs" (Cherenkov, 2006), the least expensive way to enter new markets has been determined - export sales via agents, importers and distributors. The company "Lāči" offers high quality products, which have multiple awards and quality certificates, so a standardization strategy should be chosen during a search for new 
markets. It is necessary to find markets, which would be ready to accept the already existing products of the company. Presently the company has realized the "Strategy of proven quality" for products from the matrix "Novelty attractiveness." In the future, it will be possible to develop a strategy of "Quality improvement, company image."

The Screening analysis makes it possible to create a list of high priority exporting countries by choosing from the 236 world countries with a targeted search based on statistics from the World Bank.

- 1-st filter determines market potential and includes: GNI per capita with high income level (over 15265\$), product import bans, the population of at least 3 million, distance (less than $3500 \mathrm{~km})$.

- The list of countries satisfying these conditions: Belgium, Denmark, Greece, Germany, Italy, the Czech Republic, France, Ireland, Slovakia, Spain, Sweden, Finland, Poland, Turkey, Belorussia, Croatia.

- 2-nd filter. Particularities of accepting a specific product at a given location. Selection criteria evaluated: insufficient information, import below average, customs taxes, the worst forecast of market development

- The resulting list of countries: The Czech Republic, Denmark, Ireland, Slovakia, Croatia, Germany, and Sweden.

- 3-rd filter. Specific factors influencing export. Analysis of main competitors, business conduction problems, bad forecasts of market products.

- The resulting list of perspective countries: Denmark, Ireland, Germany.

- 4-th filer. The target markets are determined, in which a company can find the strongest competitive niche, based on its competence.

Thus, only 2 countries remain: Denmark, and Ireland.

\section{Conclusions of screening analysis}

The method of screening analysis leads to the choosing of Denmark and Ireland as candidate countries for exporting. The base competition strategy for SIA "Lāči" in new markets is focused on niche differentiation. The comparison of "Lāči" with its main competitors in the target markets - "Lāči" is competitive in its pricing, despite the fact it is higher than prices of the local manufacturers. The company can position their product as a specially made product with ECO ingredients. From the International McKinsey matrix for estimation of exporting to foreign markets by SIA "Lāči" (determining an integral indicator of country attraction): the market of Denmark is highly attractive and competitive for "Lāči" while, the Irish market is highly attractive and medium competitive for "Lāči." The main strategy here is exporting via company's own representatives. In Ireland, the local population does not understand the concept of rye bread entirely however, in this country there are over 185 thousand immigrants from post-soviet countries that are familiar with this product, and they make the niche market for supplies of such a product. By using industry trends, ECO products should be introduced to target markets and benefit from low VAT rates (value added tax). When exporting products of "Lāči" to the markets of Denmark, the emphasis should be given to unique features of the product, such as high quality and handwork. When exporting products of "Lāči" to Irish markets, the high quality of the product should be emphasized, as well as the exporting country when advertising the product. In markets of Denmark the competition between trading networks and local manufacturers is high, and Germany is in close vicinity as well. On the other hand, the purchasing ability is high, and this market can be entered with niche food products. When competition increases, it should be stressed, that the product is exclusive and of Latvian origins.

\section{Conclusions}

In turbulent conditions- unpredictably and rapidly changing business environmental factors -active adaptation becomes a valid marketing technology, especially for small and medium businesses in Latvia.

The use of algorithms for standard marketing solutions allows for fast and adequate research of specific business environmental features and provides an active and adaptive marketing solution for the organization. 
The higher the turbulence in a business environment is, the more actively small and medium businesses search for new niches by using specific selection criteria.

The authors proposed algorithm is rather simple for securing international markets by small and medium businesses' marketing technologies, it shows its practicality in different businesses, times, and even the different abilities of managers.

The use of controllable solutions creativity - real opportunity to find variants for achieving goals of a business structure in conditions of a turbulent environment.

The use of a matrix of "Solutions novelty - demand for novelty by consumers" by specialists in the process of developing marketing solutions, allows them to find new aspects for development of adaptive marketing solutions.

In the presented work, the strategy development for an enterprise entering international markets has been described, the stages of decision making and choice of new target market have been analyzed. Based on an example of the enterprise "Lāči," the search for the most attractive international market has been made for this specific Latvian company.

\section{References}

Ansoff, H. I. (2007). Strategic Management Classic Edition. Palgrave Macmillan.

Bahmane, L. (2005). Cluster Analysis as the Method of Subject Segmentation of European Development Funds of Small and Medium-Sized Business in Latvia. Proceedings of the 5th International Conference "Reliability and Statistics in Transportation and Communication." Riga.

Bahmane, L. (2010). Development of Strategic Marketing Solutions in Circumstances of Rapidly Changing External Environment. Proceedings of the 10th International Conference "Reliability and Statistics in Transportation and Communication," (pp. 255-260). Riga.

Best, R. J. (2005). Market-Based Management. Strategies for Growing, Customer Value and Profitability. 4th edition. Prentice Hall.

Cherenkov, V. I. (2006). Mezhdunarodnyy biznes. Uchebno - metodicheskiy kompleks [International Business. Training and metodology complex]. Rostov na Donu: Feniks.

Hammer, M., \& Champy, D. (2009). Reengineering the Corporation: A Manifesto for Business Revolution. HarperBusiness Essentials.

Kotler, P. T., \& Keller, L. K. (2012). Marketing Management, 14th Edition. Pearson.

Lambin, J. J. (1994). Le Marketing Strategique. Une perspective europeenne. [Strategic Marketing. A European Perspective] 3-rd edition. Ediscience International.

Porter, M. E. (2008). On Competition: Updated and Expanded Edition. Boston: Harvard Business School Publishing.

Sabel, C. F., \& Prokop, E. J. (1997). Stabilizatsiya cherez reorganizatsiyu [Stabilization Through Reorganization]. Moscow: RAGS. 